\title{
CD20, AIF-1, and TGF- $\beta$ in graft-versus-host disease: a study of mRNA expression in histologically matched skin biopsies
}

\author{
Julie $\mathrm{M} \mathrm{Wu}{ }^{1}$, Christopher J Thoburn ${ }^{2}$, Joshua Wisell ${ }^{1}$, Evan R Farmer ${ }^{3}$ and Allan D Hess ${ }^{2}$ \\ ${ }^{1}$ Department of Pathology, Johns Hopkins Medical Institutions, Baltimore, MD, USA; ${ }^{2}$ Department of \\ Oncology and Immunology, Johns Hopkins Medical Institutions, Baltimore, MD, USA and ${ }^{3}$ Department \\ of Dermatology, Johns Hopkins Medical Institutions, Baltimore, MD, USA
}

\begin{abstract}
Graft-versus-host disease is the leading cause of non-relapse mortality after allogeneic bone marrow transplantation. The cell-mediated immune mechanisms that underlie the pathogenesis of graft-versus-host disease remain unclear. In this study, 47 skin biopsies representing graft-versus-host disease grades 0 -III, lichenoid, and sclerodermoid were included from 31 allogeneic bone marrow transplantation recipients. RNA from paraffin-embedded tissue was harvested. Transcript levels of the following markers were assessed and correlated with grade and survival: CD3, CD20, FoxP3, IL-17, $\gamma$-interferon (IFN- $\gamma$ ), transforming growth factor- $\beta$ (TGF- $\beta$ ), IL-6, connective tissue growth factor (CTGF), allograft inflammatory factor-1(AIF-1), and IL-13. Levels of three markers significantly correlated with the length of survival (TGF- $\beta$, correlation coefficient $-20.8, P=0.016$; AIF-1, 13.2, $P=0.016$; and CD20, 66, $P=0.027$ ). CD20 expression was limited to lichenoid cases. Levels of TGF- $\beta$, AIF-1, and IFN- $\gamma$ appeared to correlate with histological progression, but did not reach statistical significance. Expression of FoxP3 correlated with worse survival, and approached statistical significance $(P=0.053)$. Two potential mechanistic pathways were identified: the 'scleroderma' group (AIF-1 and TGF- $\beta$ ) and the 'B-cell' group (CD20). Transcript levels of these markers were implicated in the progression from acute to chronic disease, and also correlated significantly with the duration of survival. Identification of these three markers may direct therapy selection with targeted agents, including the use of rituximab when B-lymphocytes are implicated.
\end{abstract}

Modern Pathology (2010) 23, 720-728; doi:10.1038/modpathol.2010.48; published online 26 February 2010

Keywords: graft-versus-host disease; cytokines; CD20; AlF-1; skin biopsy

Development of graft-versus-host disease is a frequent and serious complication that develops after allogeneic bone marrow transplantation. Approximately $20-50 \%$ of all transplanted patients will have at least grade 2 graft-versus-host disease despite immunosuppressive prophylaxis. ${ }^{1}$ The acute phase is characterized by cutaneous eruption in the form of a morbilliform rash, purpuric lesions, plaques, or bullae. Acute graft-versus-host disease has a mortality rate of up to $30 \%$. The prognostic factors indicating progression of acute graft-versushost disease are controversial. Hymes et $a l^{2}$ reported

Correspondence: Dr AD Hess, PhD, Department of Oncology and Immunology, Johns Hopkins School of Medicine, 417 North Caroline Street, Room 302, Baltimore, MD 21287, USA.

E-mail: adhess@jhmi.edu

Received 21 July 2009; revised 1 October 2009; accepted 2 October 2009; published online 26 February 2010 that the number of dermal and epidermal mononuclear infiltrates in grade 2 biopsies correlated with the probability of developing more severe acute graft-versus-host disease. However, Darmestadt et $a l^{3}$ reported that histological parameters were not predictive of progression, but rather clinical parameters, such as stage, extent of rash, stool output, and total bilirubin, were most useful during the first 40 days after bone marrow transplantation.

Chronic graft-versus-host disease typically develops at 4 months after transplantation and is characterized by skin changes similar to that of lichen planus or scleroderma. Although chronic stage is preceded by an acute stage in $80 \%$ of patients with chronic graft-versus-host disease, the chronic form can arise de novo. ${ }^{4}$ There are no reliable histological parameters in biopsies of acute disease to prognosticate evolution to chronic disease. ${ }^{2}$ Chronic graftversus-host disease occurs in up to $60 \%$ of patients 
receiving HLA identical sibling grafts, and is the leading cause of non-relapse mortality in more than 2 years after transplant. ${ }^{5}$ Despite the serious implications of morbidity and mortality, treatment remains limited in efficacy.

The pathophysiology of graft-versus-host disease classically centers on T cells. ${ }^{6}$ Recent studies have delineated subsets of $\mathrm{T}$ cells, the balance of what seems to determine disease outcome. Recent studies have shown that CD4 + CD25 + FoxP3 + regulatory $\mathrm{T}$ cells (Tregs) are progressively lost during acute graft-versus-host disease progression, concurrent with an expansion of CD4 + T(H)17 cells. ${ }^{7}$ Moreover, expression of FoxP3 transcripts as a measure of Tregs inversely correlated with severity of graftversus-host disease, ${ }^{8}$ suggesting that a decrease in Tregs allow for the development and clinical progression of disease.

Recent studies have shown that B cells may also have a significant role in chronic graft-versus-host disease. Sarantopoulos et $a l^{9}$ found that B-cell activating factor remained elevated in a subset of patients who developed chronic graft-versus-host disease after allogeneic stem cell transplant. Treatment with rituximab, an anti-CD20 agent, has been shown to have clinical efficacy in a subgroup of patients with chronic graft-versus-host disease. ${ }^{10-12}$ Lastly, chronic graft-versus-host disease is known to share clinical and serologic features with collagen vascular diseases, such as autoimmune hepatitis, Sjogren's syndrome, and especially systemic sclerosis. ${ }^{13,14}$ Patients with chronic graft-versus-host disease harbor auto-antibodies such as antinuclear, anti-smooth muscle, and anti-mitochondrial antibodies that overlap with autoimmune disorders.

The involvement of $\mathrm{T}$ cells, $\mathrm{B}$ cells, and the association with collagen vascular diseases poses a complex picture of pathogenesis. Moreover, these associations were primarily shown in studies of serum markers and peripheral blood mononuclear cells, which raise the question of their involvement at the actual sites of disease. The current studies used skin biopsy samples of graft-versus-host disease to dissect the pathology of this disorder at the site of tissue destruction. Pro-inflammatory cytokine gene expression was quantified in histologically matched skin biopsy samples. The in situ analysis of slides from formalin-fixed, hematoxylin and eosin (H\&E)-stained skin biopsies provided for the direct confirmation of disease with the cytokine gene expression. This study was divided into four parts. The corresponding markers were evaluated to assess: (1) the role of B cells versus T cells: CD20 and CD3; (2) Tregs versus T(H)17 subsets: FoxP3 and IL-17; (3) cytokines involved in systemic sclerosis: connective tissue growth factor (CTGF), allograft inflammatory factor-1 (AIF-1), and IL-13; and (4) cytokines implicated in acute and chronic graftversus-host disease: $\gamma$-interferon (IFN- $\gamma$ ), transforming growth factor- $\beta$ (TGF- $\beta$ ), and IL-6. Analysis of these cytokine and lymphocyte markers at the site of tissue destruction may provide unique insights into the diverging avenues of pathogenicity in graft-versus-host disease.

\section{Materials and methods}

\section{Material Selection}

A total of 47 skin biopsies obtained between 2000 and 2007 were retrieved from Johns Hopkins Surgical Pathology archives. Biopsies were taken from a total of 31 patients with previous allogeneic bone marrow transplantation, who showed skin changes clinically suspicious for graft-versus-host disease. Cases were chosen to represent all grades of graft-versus-host disease: none, grades I-III, lichenoid (L), and sclerodermoid (S). Biopsies that showed no evidence of graft-versus-host disease, showed nonspecific changes such as focal parakeratosis with sparse perivascular infiltrate, subacute spongiotic dermatitis with eosinophils, and focal interface dermatitis without additional features classic for graft-versus-host disease, such as dyskeratotic cells and follicular involvement. Chart review was conducted on all cases to confirm clinical diagnosis of graft-versus-host disease and document disease progression and survival. Involvement by graft-versus-host disease of other organ systems and immunosuppressive regimen used after transplantation were also noted.

\section{Histological Review}

All biopsy materials were reviewed by two investigators for grading of graft-versus-host disease (JMW and JAW). These specimens were reviewed independently without knowledge of previous diagnosis, clinical condition, therapeutic regimen, or outcome. In approximately $10 \%$ of cases in which a discordant grade was rendered, the discrepancies were resolved by reading the specimen again together. Biopsies were graded according to the following criteria (Figure 1): grade I: basal vacuolopathy; grade II: two or more necrotic keratinocytes, epidermotrophic lymphocytic infiltrate; grade III: focal dermato-epidermal separation and cleft formation; lichenoid: lichenoid infiltrate, basal cell hydropic degeneration; and sclerodermoid: epidermal atrophy with loss of rete ridges, fibrosis of the superficial, and deep dermis.

\section{RNA Extraction and cDNA Synthesis}

Three unstained formalin-fixed, paraffin-embedded serial sections were obtained for each biopsy block whereas a fourth section was stained with H\&E. The material from the unstained sections was scraped off the glass slide with a razor blade into a $1.5 \mathrm{ml}$ Eppendorf tube. A total of $250 \mu \mathrm{l}$ of $0.5 \%$ Tween-20 was added and the tube was incubated at $99{ }^{\circ} \mathrm{C}$ for 

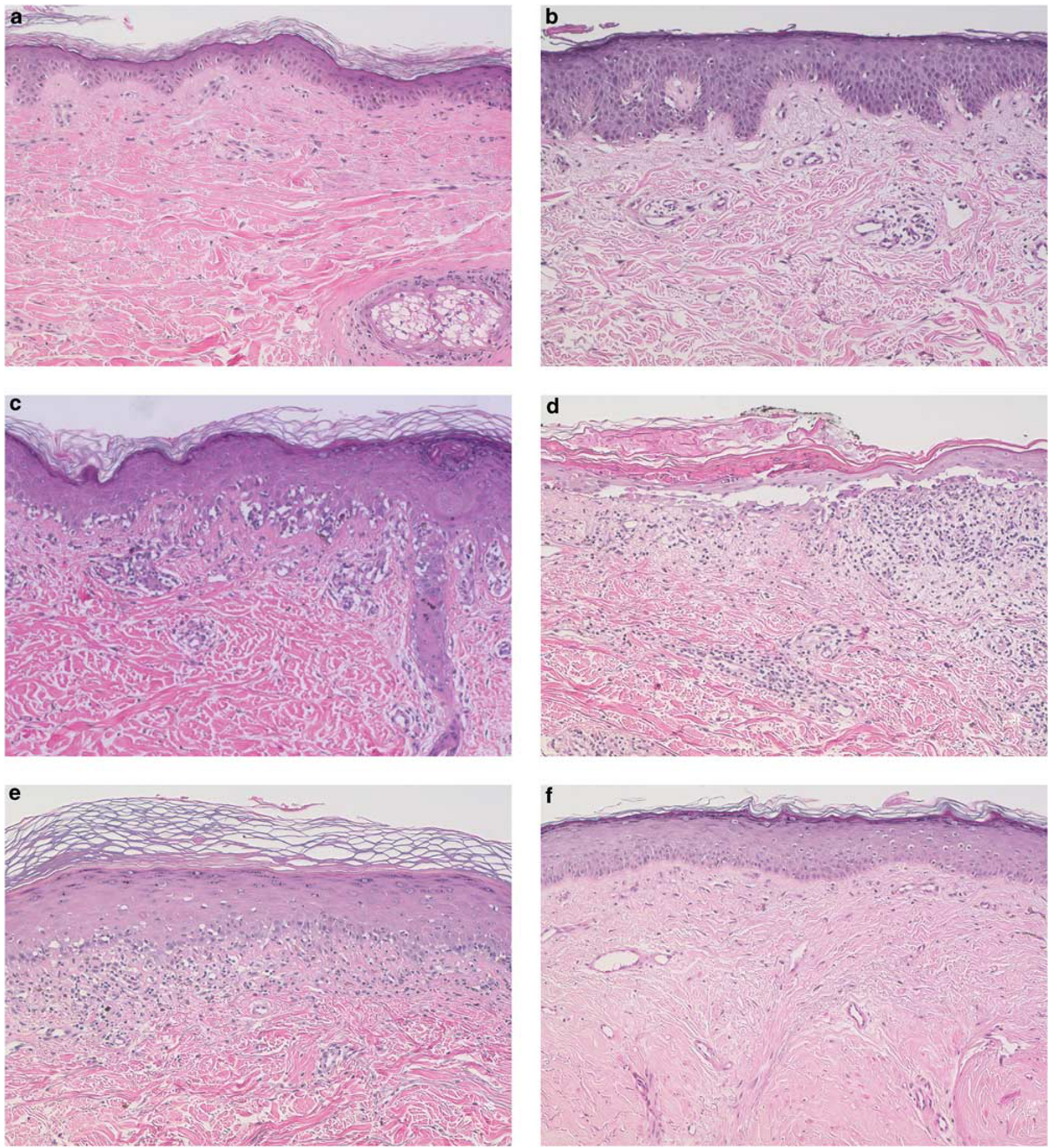

Figure 1 Representative skin biopsies. (a) No evidence of GVHD; (b) grade 1 GVHD; (c) grade 2 GVHD; (d) grade 3 GVHD; (e) lichenoid GVHD; and (f) sclerodermoid GVHD. All biopsies were stained with hematoxylin and eosin, $\times 40$ magnification.

$5 \mathrm{~min}$, spun at $10000 \mathrm{~g}$ for $15 \mathrm{~s}$, and incubated at $99^{\circ} \mathrm{C}$ for $5 \mathrm{~min}$. The material was then centrifuged at $10000 \mathrm{~g}$ for $10 \mathrm{~min}$ at room temperature. The waxy layer was removed and discarded. RNA was isolated with ethanol extraction and standard Trizol method. Complementary DNA templates were synthesized using Ready-To-Go You-Prime First-Strand Beads (GE Healthcare, Piscataway, NJ, USA).

\section{Markers Studied}

RNA transcript levels were analyzed for CD3, IFN- $\gamma$, FoxP3, and TGF- $\beta$ for all 47 cases: no graft-versushost disease ( 7 cases), grade I ( 7 cases), grade II (11 cases), grade 3 (6 cases), lichenoid (9 cases), and sclerodermoid ( 7 cases). In addition, transcripts levels of CD20, IL-6, and AIF-1 were analyzed on a 
subset of cases: no graft-versus-host disease (4 cases), grade III ( 2 cases), lichenoid (6 cases), and sclerodermoid (5 cases).

\section{Quantitative PCR}

Quantitative PCR was performed using the Taq PCR Master Mix Kit (Qiagen, Valencia, CA, USA) on the 7500 Real-Time PCR System (Applied Biosystems, Carlsbad, CA, USA). Target primers labeled with FAM were obtained from ABI (Carlsbad, CA, USA). GADPH primers were labeled with VIC and obtained from ABI. Cycling conditions were as follows: step 1: incubation at $50{ }^{\circ} \mathrm{C}$ for $2 \mathrm{~min}$; step 2: denaturation at $95{ }^{\circ} \mathrm{C}$ for $10 \mathrm{~min}$; and step 3 : denaturation at $95{ }^{\circ} \mathrm{C}$ for $15 \mathrm{~s}$, primer extension at $60^{\circ} \mathrm{C}$ for $1 \mathrm{~min}$, followed by a total of 50 cycles.

\section{Data Analysis}

RNA transcript levels for cytokine and lymphocyteassociated marker were standardized against mRNA transcript for the housekeeping gene, GADPH. Quantitative PCR was performed in triplicate and the means of the test samples were analyzed in relation to histological diagnosis, patient characteristics (age and sex), and clinical outcome (overall survival, disease-free survival, and length of survival). Associations were evaluated using logistic and linear regressions. Statistical analysis was conducted using STATA software, version 8 (STATA, College Station, TX, USA).

\section{Results}

A total of 47 biopsies were obtained from 31 patients who were suspected of having developed clinical signs of graft-versus-host disease after allogeneic bone marrow transplant. The average age was 42.7 years (ranging from 3 months to 64 years), and the male to female ratio was 26:5. The average length of follow-up was 31 months, and 5 patients were lost to follow-up. The patients lost to follow-up included two cases of acute grade 2 disease, one case with lichenoid graft-versus-host disease, and two cases of sclerodermoid graft-versus-host disease. One case (acute grade 2 on biopsy) was refractory to immunosuppressive therapy and portended poor outcome, whereas the clinical progression of the remaining four cases were ambivalent. The number of cases is listed in Table 1.

Transcript levels of all detectable markers are shown in Figure 2. IFN- $\gamma$ mRNA transcripts were highest in skin biopsies from patients with lichenoid graft-versus-host disease (1.02 \pm 0.143 s.e.) compared with patients with acute graft-versus-host disease (grade I, $0.599 \pm 0.253$ s.e.; grade II, $0.767 \pm$ 0.168 s.e.; and grade III, $0.496 \pm 0.228$ s.e.). TGF- $\beta$ mRNA transcript levels were greatest in the biopsies
Table 1 Summary of cases

\begin{tabular}{lcc}
\hline GVHD grade & $\begin{array}{c}\text { Number of } \\
\text { cases }\end{array}$ & $\begin{array}{c}\text { Average survival } \\
\text { (months) }\end{array}$ \\
\hline 0 & 7 & 34 \\
1 & 7 & 37 \\
2 & 11 & 25 \\
3 & 6 & 18 \\
$\mathrm{~L}$ & 9 & 31 \\
S & 7 & 62
\end{tabular}

GVHD (graft-versus-host disease) grade $0=$ no histological evidence of graft-versus-host disease; $\mathrm{L}=$ lichenoid; $\mathrm{S}=$ sclerodermoid.

Average survival is months of survival after allogeneic bone marrow transplantation.

The number of cases includes five patients who were lost to follow-up (acute grade 2, two cases; lichenoid, one case; and sclerodermoid, one case).

form chronic graft-versus-host disease patients (lichenoid, $0.936 \pm 0.102$ s.e. and sclerodermoid, $174 \pm 173$ s.e.) compared with patients with acute graft-versus-host disease (grade III, $0.570 \pm 0.170$ s.e.). Similarly, the levels of AIF-1 transcripts were greatest in chronic graft-versus-host disease (grade III, $0.00599 \pm 0.00268$ s.e.; lichenoid, $0.728 \pm 0.639$, and sclerodermoid $0.718 \pm 0.758$ s.e.). Levels of the TGF- $\beta$, AIF-1, and IFN- $\gamma$ appeared increased from acute to chronic stages of graft-versus-host disease. Although these trends were apparent by inspection, they did not reach statistical significance.

Of the 10 markers evaluated, three correlated significantly with the duration of survival after bone marrow transplantation (Table 2). TGF- $\beta$ mRNA transcript levels negatively correlated with the length of survival $(-20.8, P=0.016)$ whereas AIF-1 and CD20 transcript levels positively correlated with the length of survival (13.2, $P=0.016$ and 66.0, $P=0.027$ ). Expression levels of TGF- $\beta$ did not correlate with either AIF-1 or CD20 $(P=0.772$ and $P=0.985$ ). Levels of FoxP3 transcripts approached statistical significance, and were negatively correlated with the length of survival $(-5.06, P=0.053)$.

The presence of CD20 transcripts was dependent on histological grade. Transcripts of CD20 were not found in biopsies showing nonspecific chronic dermatitis, that is, focal parakeratosis with sparse perivascular infiltrate, sparse perivascular infiltrate with dermal melanosis, dermatitis with changes suggestive of contact dermatitis, or subacute spongiotic dermatitis with eosinophils and focal interface inflammation. Similarly, CD20 transcripts were not detected in grade III graft-versus-host disease and sclerodermoid graft-versus-host disease. CD20 transcripts were only identified in cases of lichenoid graft-versus-host disease $(0.145 \pm 0.124$ s.e. $)$. Of the six lichenoid cases examined, two patients showed quantifiable CD20 transcripts. The first patient (CD20 mRNA transcript $=0.758$ ) had liver and skin involvement and died secondary to infection at 86 months after transplant. The second patient had lower levels of CD20 transcripts (0.0592) but died 

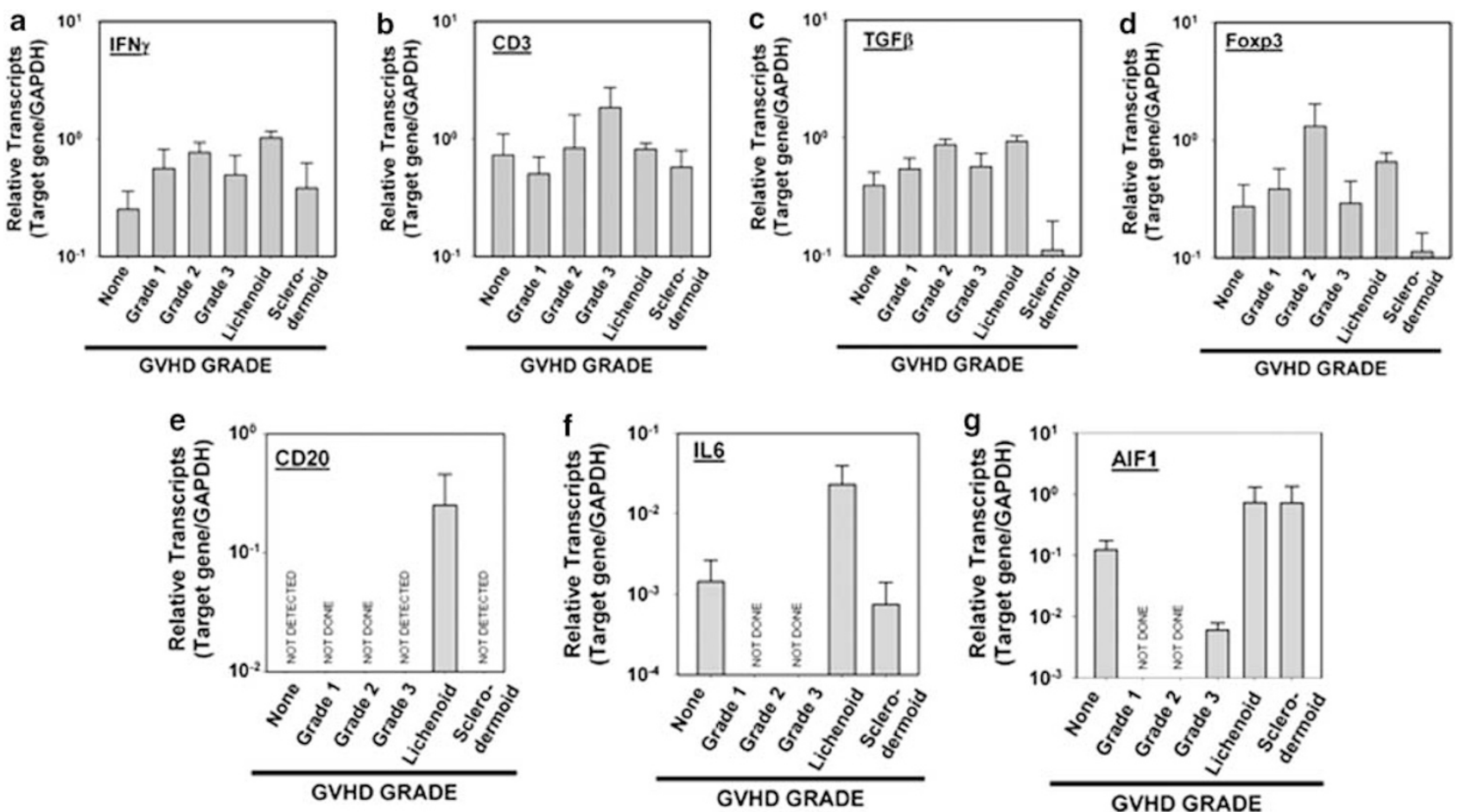

Figure 2 Messenger RNA transcript levels relative to histological grade. The $y$ axis represents mRNA transcript levels in logarithmic scale, relative to GADPH transcript levels. The $x$ axis represents GVHD histological grade: none $=$ no GVHD. Error bars represent s.e. (a-d) GVHD grades evaluated included no GVHD, grade 1, grade 2, grade 3, lichenoid, and sclerodermoid. (e-g) GVHD grades evaluated included no GVHD, grade 3, lichenoid, and sclerodermoid only.

Table 2 Linear regression data in relation to survival

\begin{tabular}{lcc}
\hline Variables & Coefficient & P-value \\
\hline TGF- $\beta$ & -20.8 & 0.016 \\
AIF-1 & 13.2 & 0.016 \\
CD20 & 66.0 & 0.027 \\
FoxP3 & -5.06 & 0.053 \\
IFN- $\gamma$ & -9.14 & 0.130 \\
Age & 0.225 & 0.228 \\
GVHD grade & 2.10 & 0.342 \\
Sex & -8.68 & 0.373 \\
CD3 & -1.40 & 0.687 \\
IL-6 & 203 & 0.709
\end{tabular}

TGF- $\beta=$ transforming growth factor- $\beta$; AIF-1 = allograft inflammatory factor 1 ; IFN- $\gamma=$ interferon- $\gamma$.

GVHD (graft-versus-host disease) grade ranged included none, grades $1-3$, lichenoid, and sclerodermoid.

Survival is the length of survival (in months) after allogeneic bone marrow transplant.

1 month after transplant. This patient had a followup biopsy 2 months later showing again lichenoid graft-versus-host disease, but no detectable CD20 mRNA transcripts. The patient was a 3-month-old male who died 15 months after bone marrow transplantation secondary to infection. Of the remaining three cases with no demonstrable CD20 transcripts, one patient has survived 19 months after bone marrow transplantation and has no evidence of graft-versus-host disease. The two remaining patients were lost to follow-up.

Gastrointestinal involvement was found in 8 of 47 cases. There was no correlation between GI involvement and cutaneous graft-versus-host disease grade, survival, or transcript levels. Similarly, type of posttransplant immunosuppressive regimen used did not correlate with graft-versus-host disease grade, progression, survival, or transcript levels.

On multivariate analysis, grade of graft-versushost disease significantly correlated with overall survival $(P=0.048)$. No marker correlated with overall survival or disease-free survival. There was no correlation found with either diagnosis or survival with transcript levels of CD3 or IL-6. RNA transcripts of IL-17, IL-13, and CTGF were not detected.

\section{Discussion}

Although many cytokines have been implicated in graft-versus-host disease, most markers were shown in the serum or from peripheral blood lymphocytes with unknown pathophysiological implications at the actual sites of disease. Furthermore, emerging studies show divergent mechanisms of pathogenicity, ranging from $\mathrm{T}$ cells to $\mathrm{B}$ cells to collagen 
vascular disease pathways. To further define pathologic mechanisms in graft-versus-host disease, cytokine gene expression profiles representing distinct immunological subsets were evaluated in histologically matched skin biopsies. The interpretation of results is divided into three parts: (1) sclerodermalike subset, as defined by TGF- $\beta$ and AIF-1; (2) B-cell subset, as defined by CD20; and (3) T-cell subset, as defined by CD3, IL-17, and FoxP3.

\section{'Scleroderma-Type’ Markers}

RNA transcript expression levels for two cytokines, TGF- $\beta$ and AIF-1, were found to be dominantly associated with the transition from acute to chronic disease. Importantly, levels of mRNA transcripts for these two cytokine were also found to significantly correlate with the length of survival after allogeneic bone marrow transplantation.

The role of TGF- $\beta$ in graft-versus-host disease is complex. Banovic et al ${ }^{15}$ has shown that early TGF- $\beta$ attenuates acute graft-versus-host disease, whereas late expression of TGF- $\beta$ mediated chronic graftversus-host disease. In serologic studies, TGF- $\beta$ has also been shown to be increased during the development of chronic graft-versus-host disease. ${ }^{16}$ The present study shows a similar pattern of increased expression in chronic graft-versus-host disease with a negative correlation between survival duration and TGF- $\beta$ transcript levels.

The relationship of AIF-1 and graft-versus-host disease has not been previously described. In the present study, there was a correlation between AIF-1 transcript levels and progression of graft-versus-host disease. Allograft inflammatory factor is a calciumbinding protein first identified in the context of chronic cardiac rejection. ${ }^{17-19}$ More recently, AIF-1 protein expression has been shown to be elevated in skin and peripheral blood cell samples from patients with systemic sclerosis. ${ }^{20,21}$ Because of the clinical similarities between systemic sclerosis and chronic graft-versus-host disease, this cytokine was included in the study. AIF-1 mRNA transcript levels not only correlated with chronic graft-versus-host disease, but also showed a significant, positive correlation with the length of survival. This finding is surprising as progression to chronic disease is thought to be related with decreased survival. However, as AIF-1 is implicated in systemic sclerosis, perhaps this marker defines a subset of chronic graft-versus-host disease that may have better prognosis.

Upon further examination, TGF- $\beta$ and AIF-1 share several features. Both cytokines are presumed to be expressed by T lymphocytes. Similar to AIF-1, TGF- $\beta$ has been implicated in systemic sclerosis. ${ }^{22,23}$ Both cytokines induced collagen expression from dermal fibroblasts. ${ }^{23,24}$ Finally, the two seem to be involved in a positive feedback cycle, as AIF-1 has been shown to induce TGF- $\beta$ production by dermal fibroblasts, ${ }^{24}$ and stimulation of peripheral blood mononuclear cells with TGF- $\beta$ caused a significant increase of AIF-1 transcription. ${ }^{20}$ This relationship was not observed in the present study, as AIF-1 and TGF- $\beta$ expression levels showed no significant correlation $(P=0.701)$.

Owing to their involvement in collagen production and their mutually enhancing signals, the finding of increased expression of both AIF-1 and TGF- $\beta$ in chronic graft-versus-host disease is not unexpected. However, their diverging effect on survival was surprising. High expression of TGF- $\beta$ was associated with a negative effect on survival duration (correlation coefficient $-20.8, P=0.016$ ) whereas high expression of AIF-1 was associated with a positive effect on survival length (correlation coefficient 13.2, $P=0.016$ ). This difference may be explained by the therapeutic regimen used, which may selectively target one pathway. An alternative explanation, discussed previously, is that AIF-1 defines a subset of graft-versus-host disease that may have a better prognosis.

\section{B-Cell Involvement}

The expression of CD20 was used as a surrogate marker for B-cell presence. Although a range of graftversus-host disease grades were analyzed (none, grade III, lichenoid, and sclerodermoid), only the lichenoid subset showed detectable CD20 transcript levels. Of the six lichenoid graft-versus-host disease cases studied, two showed detectable levels of CD20. These two cases also had improved survival after bone marrow transplantation compared with cases showing absent CD20 mRNA transcripts. Of the markers analyzed, levels of CD20 transcript showed the highest positive correlation with survival duration (correlation coefficient 66.0, $P=0.027$ ). The finding of CD20 transcripts implicates B-cell involvement in a subset of chronic graft-versus-host disease, and the correlation with survival suggests an improved prognosis for this subset.

Although B-cell involvement in graft-versus-host disease is not canonically accepted, its role is supported by several recent studies showing clinical improvement of chronic graft-versus-host disease patients when treated with rituximab. ${ }^{10-12}$ In the present study, the identification of CD20-positive cells in lichenoid graft-versus-host disease raises the tantalizing possibility of predicting response to rituximab based on immunohistochemical evaluation of skin biopsy samples.

\section{T-Cell Involvement}

Graft-versus-host disease has been thought to be a T cell-driven process. Furthermore, recent interesting T-cell subsets have highlighted the interplay between autoinflammatory $\mathrm{T}(\mathrm{h}) 17$ subsets and regulatory FoxP3 $+\mathrm{T}$ cells in disease of conditions such as inflammatory bowel disease and multiple 
sclerosis. ${ }^{25,26}$ To delineate the role of T-cell subsets in graft-versus-host disease, transcript levels of CD3, IL-17, and FoxP3 were analyzed.

Levels of CD3 were highest in grade III graftversus-host disease, but did not reach statistical significance. IL-17 mRNA transcripts were not detected. Levels of FoxP3 were greatest in grade II graft-versus-host disease, but again, there was no statistically significant correlation between grade and transcript level. The presence of increased Foxp3 transcripts in the tissue suggests that the Tregs are infiltrating the tissues in an attempt to suppress the alloreactive $\mathrm{T}$ cells and abrogate graft-versus-host disease. On the other hand, there was a negative correlation between FoxP3 mRNA transcript levels and duration of survival, which approached statistical significance (correlation coefficient $-5.06, P=0.053$ ). This negative association is surprising, given that previous studies have shown a suppression of graftversus-host disease severity with increased FoxP3 mRNA expression and increased numbers of FoxP3 (+) T cells. ${ }^{8,27}$ However, both studies were performed on peripheral blood mononuclear cells, rather than at the sites of graft-versus-host disease involvement. Furthermore, Fujita et $a l^{27}$ used a mouse model, whereas Miura et $a l^{8}$ studied two groups of post-bone marrow transplantation patients, one with pharmacologically induced graft-versus-host disease after autologous bone marrow transplantation and the other with graft-versus-host disease occurring after allogeneic bone marrow transplantation with calcineurininhibitor-based immunosuppression. It is possible that FoxP3(+) T cells may modulate graft-versus-host disease severity in the peripheral circulation, which may alter the cellular makeup at the sites of disease. CD3 transcript levels showed no correlation with either graft-versus-host disease grade or survival duration. Instead, transcript levels remained relatively constant throughout all grades of graft-versushost disease. This pattern suggests that although $\mathrm{T}$ cells make up the background milieu of graftversus-host disease, they are not determinants of stage progression or prognosis. As both AIF-1 and TGF- $\beta$ can be produced by $\mathrm{T}$ lymphocytes, more studies are needed to establish the cellular origin of these cytokines in the graft-versus-host disease setting. These results, taken together with the absence of IL-17 and the negative correlation between FoxP3 and survival, suggest that graft-versus-host disease in humans may be more complex with distinct, $\mathrm{T}$ cell subset-mediated immune mechanisms.

\section{Other Markers}

There were several significant negative results from this study. Although there was a correlation with AIF-1, there was no correlation with other cytokines implicated in scleroderma, such as $\mathrm{CTGF}^{28,29}$ or IL-13. ${ }^{30}$ IL-6 and IFN- $\gamma$ were previously shown to be associated with cutaneous graft-versus-host disease. $^{31-34}$ Although the expression of IFN- $\gamma$ correlated with chronic graft-versus-host disease by inspection, it did not reach statistical significance and there was no association with survival. The expression of IL-6 was not found to correlate with diagnosis or survival.

This study is based on mRNA transcript levels to provide a quantitative approach to cytokine analysis. Several studies have shown a correlation between mRNA transcript and protein levels, ${ }^{35-37}$ including one correlating Foxp3 gene expression with protein content in Tregs. ${ }^{38}$ The advantages of studying mRNA transcripts are that they are arguably more sensitive than immunohistochemistry studies on paraffin blocks, which may be affected by formalin fixation, and that they allow for a finer degree of quantitation. Nevertheless, future studies are needed to show protein expression by immunohistochemistry. Lastly, immunohistochemical studies are required to localize the cellular elaborators (ie, T cells, B cells, macrophages, etc) of these transcripts.

\section{Summary}

This study identified three potential markers (AIF-1, TGF- $\beta$, and CD20) that have implications on graftversus-host disease prognosis, and may also represent viable therapeutic targets. Two pathways of disease mechanism emerge from the differential expression of the above markers: one that shares similarity with connective tissue disorders (AIF-1and/or TGF- $\beta$-positive cases), and the other that involves B lymphocytes (CD20-positive cases). The identification of these markers in skin biopsy specimens may portend prognosis as well as treatment response. Although T-lymphocyte markers did not correlate with disease progression or survival, it is possible that $\mathrm{T}$ cells may have a role in both pathways, elaborating AIF-1 and TGF- $\beta$, or recruiting and activating $\mathrm{B}$ cells. Thus, the role of $\mathrm{T}$ lymphocytes remains to be elucidated.

Clinically, graft-versus-host disease seems to be a composite of autoimmunity and allograft-driven inflammation. This study shows that although this heterogeneity is mirrored on a mechanistic level, distinct pathways as defined by specific markers can be identified with prognostic and treatment implications.

\section{Acknowledgement}

This study was supported by Grant CA15396, from National Cancer Institute (National Institutes of Health).

\section{Disclosure/conflict of Interest}

The authors declare no conflict of interest. 


\section{References}

1 Ball LM, Egeler RM. Acute GvHD: pathogenesis and classification. Bone Marrow Transplant 2008;41(Suppl 2):S58-S64.

2 Hymes SR, Farmer ER, Lewis PG, et al. Cutaneous graft-versus-host reaction: prognostic features seen by light microscopy. J Am Acad Dermat 1985;12: 468-474.

3 Darmstadt GL, Donnenberg AD, Vogelsang GB, et al. Clinical, laboratory, and histopathologic indicators of the development of progressive acute graft-versus-host disease. J Invest Dermatol 1992;99:397-402.

4 Matsuoka LY. Graft versus host disease. J Am Acad Dermat 1981;5:595-599.

5 Lee SJ, Vogelsang G, Flowers ME. Chronic graft-versushost disease. Biol Blood Marrow Transplant 2003;9:215-233.

6 Baird K, Pavletic SZ. Chronic graft versus host disease. Curr Opin Hematol 2006;13:426-435.

7 Chen X, Vodanovic-Jankovic S, Johnson B, et al. Absence of regulatory T-cell control of $\mathrm{TH} 1$ and TH17 cells is responsible for the autoimmunemediated pathology in chronic graft-versus-host disease. Blood 2007;110:3804-3813.

8 Miura Y, Thoburn CJ, Bright EC, et al. Association of Foxp3 regulatory gene expression with graft-versushost disease. Blood 2004;104:2187-2193.

9 Sarantopoulos S, Stevenson KE, Kim HT, et al. High levels of B-cell activating factor in patients with active chronic graft-versus-host disease. Clin Cancer Res 2007;13:6107-6114.

10 Cutler C, Miklos D, Kim HT, et al. Rituximab for steroid-refractory chronic graft-versus-host disease. Blood 2006;108:756-762.

11 Zaja F, Bacigalupo A, Patriarca F, et al. Treatment of refractory chronic GVHD with rituximab: a GITMO study. Bone Marrow Transplant 2007;40: 273-277.

12 Ratanatharathorn V, Ayash L, Reynolds C, et al. Treatment of chronic graft-versus-host disease with anti-CD20 chimeric monoclonal antibody. Biol Blood Marrow Transplant 2003;9:505-511.

13 Rouquette-Gally AM, Boyeldieu D, Gluckman E, et al. Autoimmunity in 28 patients after allogeneic bone marrow transplantation: comparison with Sjogren syndrome and scleroderma. Br J Haematol 1987;66: 45-47.

14 Rouquette-Gally AM, Boyeldieu D, Prost AC, et al. Autoimmunity after allogeneic bone marrow transplantation. A study of 53 long-term-surviving patients. Transplantation 1988;46:238-240.

15 Banovic T, MacDonald KP, Morris ES, et al. TGF-beta in allogeneic stem cell transplantation: friend or foe? Blood 2005;106:2206-2214.

16 Liem LM, Fibbe WE, van Houwelingen $\mathrm{HC}$, et al. Serum transforming growth factor-beta1 levels in bone marrow transplant recipients correlate with blood cell counts and chronic graft-versus-host disease. Transplantation 1999;67:59-65.

17 Kelemen SE, Autieri MV. Expression of allograft inflammatory factor-1 in T lymphocytes: a role in Tlymphocyte activation and proliferative arteriopathies. Am J Pathol 2005;167:619-626.

18 Utans U, Arceci RJ, Yamashita Y, et al. Cloning and characterization of allograft inflammatory factor-1: a novel macrophage factor identified in rat cardiac allografts with chronic rejection. J Clin Invest 1995;95:2954-2962.

19 Utans U, Quist WC, McManus BM, et al. Allograft inflammatory factory-1. A cytokine-responsive macrophage molecule expressed in transplanted human hearts. Transplantation 1996;61:1387-1392.

20 Del Galdo F, Maul GG, Jimenez SA, et al. Expression of allograft inflammatory factor 1 in tissues from patients with systemic sclerosis and in vitro differential expression of its isoforms in response to transforming growth factor beta. Arthritis Rheum 2006;54: 2616-2625.

21 Tan FK, Zhou X, Mayes MD, et al. Signatures of differentially regulated interferon gene expression and vasculotrophism in the peripheral blood cells of systemic sclerosis patients. Rheumatology (Oxford) 2006;45:694-702.

22 Ihn H. Autocrine TGF-beta signaling in the pathogenesis of systemic sclerosis. J Dermatol Sci 2008; 49:103-113.

23 Ihn $\mathrm{H}$, Yamane $\mathrm{K}$, Kubo $\mathrm{M}$, et al. Blockade of endogenous transforming growth factor beta signaling prevents up-regulated collagen synthesis in scleroderma fibroblasts: association with increased expression of transforming growth factor beta receptors. Arthritis Rheum 2001;44:474-480.

24 Del Galdo F, Jimenez SA. T cells expressing allograft inflammatory factor 1 display increased chemotaxis and induce a profibrotic phenotype in normal fibroblasts in vitro. Arthritis Rheum 2007;56:3478-3488.

25 Kolls JK, Linden A. Interleukin-17 family members and inflammation. Immunity 2004;21:467-476.

26 Cools N, Ponsaerts P, Van Tendeloo VF, et al. Regulatory $\mathrm{T}$ cells and human disease. Clin Dev Immunol 2007;2007:89195

27 Fujita S, Sato Y, Sato K, et al. Regulatory dendritic cells protect against cutaneous chronic graft-versushost disease mediated through CD4+CD25+Foxp3+ regulatory T cells. Blood 2007;110:3793-3803.

28 Igarashi A, Nashiro K, Kikuchi K, et al. Connective tissue growth factor gene expression in tissue sections from localized scleroderma, keloid, and other fibrotic skin disorders. J Invest Dermatol 1996;106:729-733.

29 Igarashi A, Nashiro K, Kikuchi K, et al. Significant correlation between connective tissue growth factor gene expression and skin sclerosis in tissue sections from patients with systemic sclerosis. J Invest Dermat 1995;105:280-284.

30 Aliprantis AO, Wang J, Fathman JW, et al. Transcription factor T-bet regulates skin sclerosis through its function in innate immunity and via IL-13. Proc Natl Acad Sci USA 2007;104:2827-2830.

31 Ochs LA, Blazar BR, Roy J, et al. Cytokine expression in human cutaneous chronic graft-versus-host disease. Bone Marrow Transplant 1996;17:1085-1092.

32 Ritchie D, Seconi J, Wood C, et al. Prospective monitoring of tumor necrosis factor alpha and interferon gamma to predict the onset of acute and chronic graft-versus-host disease after allogeneic stem cell transplantation. Biol Blood Marrow Transplant 2005;11:706-712.

33 Imamura M, Hashino S, Kobayashi H, et al. Serum cytokine levels in bone marrow transplantation: synergistic interaction of interleukin-6, interferongamma, and tumor necrosis factor-alpha in graftversus-host disease. Bone Marrow Transplant 1994;13:745-751. 
34 Barak V, Levi-Schaffer F, Nisman B, et al. Cytokine dysregulation in chronic graft versus host disease. Leuk Lymphoma 1995;17:169-173.

35 Greenbaum D, Colangelo C, Williams K, et al. Comparing protein abundance and MRNA expression levels on a genomic scale. Genome Biol 2003;4:117.

36 Jansen R, Greenbaum D, Gerstein M. Relating wholegenome expression data with protein-protein interactions. Genome Res 2002;12:37-46.
37 Shakir R, Ngo N, Naresh KN. Correlation of cyclin D1 transcript levels, transcript type and protein expression with proliferation and histology among mantle cell lymphoma. J Clin Pathol 2008;61: 920-927.

38 Capriotti E, Vonderheid EC, Thoburn CJ, et al. Expression of T-plastin, FoxP3 and other tumor-associated markers by leukemic T-cells of cutaneous T-cell lymphoma. Leuk Lymphoma 2008;49:1190-1201. 